\title{
PATOLOGIAS DA LIBERDADE: PROBLEMAS DAS NORMAS OU DOS SUJEITOS?
}

PATHOLOGIES OF FREEDOM: PROBLEMS OF NORMS OR SUBJECTS?

Bárbara Buril*

\section{RESUMO}

Os diagnósticos das patologias das liberdades jurídica e moral, elaborados pelo filósofo frankfurtiano Axel Honneth em $O$ direito da liberdade, são abordados neste artigo segundo as suas complexidades sintomatológicas, mas também em suas incompletudes etiológicas (causais), a fim de mostrar que o déficit etiológico nesses diagnósticos está relacionado ao uso da reconstrução normativa como método pelo filósofo. Na primeira parte, defenderemos como os limites na concepção de liberdade jurídica são responsáveis pelo surgimento da incapacidade de estabelecer relações sociais afetivas (I). Em seguida, observaremos como, segundo Honneth, a concepção de liberdade moral é capaz de promover sofrimentos como rigidez e engessamento (II). Nessas duas seções, mostraremos como Honneth desenvolve uma etiologia limitada em ambos os diagnósticos. Por último, desenvolveremos a concepção de liberdade social proposta por Honneth (III), sem deixar de apontar como a crítica das patologias sociais se desmobiliza dentro de um espectro de pressupostos que apenas vê "desenvolvimentos errados de normas corretas", e não "desenvolvimentos corretos de normas problemáticas" nas esferas de realização individual dos sujeitos, segundo a lógica metodológica da reconstrução normativa (IV).

PALAVRAS-CHAVE: Axel Honneth. Patologias sociais. Liberdade. Teoria crítica. Reconstrução normativa.

\section{ABSTRACT}

The diagnoses of the pathologies of legal and moral freedom, elaborated by the Frankfurtian philosopher Axel Honneth in Freedom's Right, are elaborated in this article according to their symptomatological complexities, but also in their etiological (causal) incompleteness in order to defend that the etiological deficit in these diagnoses is related to the use of normative reconstruction as a method by the philosopher. In the first part, we are going to see how the limits in the conception of legal freedom are responsible for the arising of the inability to establish affective social relationships (I). Then, we are going to observe how the conception of moral freedom promotes sufferings such as stiffness and casting. In these two initial sections, we will show how Honneth develops a deficient causal explanation for both diagnoses. Finally, we are going to develop the conception of social freedom proposed by Honneth (III), while pointing out how the critique of social pathologies is demobilized within a spectrum of presuppositions that only sees "wrong developments of correct norms", not

\footnotetext{
* Mestre em Filosofia pelo Programa de Pós-Graduação em Filosofia da Universidade Federal de Pernambuco (UFPE). E-mail: baiburil@gmail.com.
} 
"correct developments of problematic norms" in the spheres of individual realization, according to the methodological logic of normative reconstruction (IV).

KEYWORDS: Axel Honneth. Social pathologies. Freedom. Critical theory. Normative reconstruction.

Artistas falam muito sobre liberdade. Então, retomando a expressão "free as a Bird", Morton Feldman foi para um parque um dia e passou algum tempo assistindo nossos amigos emplumados. Quando ele voltou, disse, "Sabe? Eles não são livres: eles estão lutando por pedaços de comidas!"

(CAGE, 1973).

\section{INTRODUÇÃO}

Nas obras $O$ direito da liberdade e Sofrimento de indeterminação, Axel Honneth, inspirado no diagnóstico hegeliano tecido na obra Filosofia do direito, desenvolve a ideia de que concepções limitadas de liberdade individual, quando absolutizadas, levariam a patologias sociais caracterizadas por um "sofrimento de indeterminação". Para Honneth, seguindo Hegel (2010), quando duas concepções de liberdade específicas, a jurídica e a moral, são interpretadas de maneira errônea e tomadas de modo absoluto, independentemente de contextos sociais específicos, surgiriam patologias sociais que se infiltrariam, de maneira nem sempre evidente, em diferentes experiências individuais e sociais.

Para Hegel (2010), o fato de que conceitos incompletos de liberdade são capazes de afetar as subjetividades resulta de que tais conceitos não são apenas ideias abstratas, situadas separadamente dos sujeitos, mas formas do "espírito objetivo" que estão imbricadas em instituições, comportamentos e modos de ser nas sociedades modernas. Na Filosofia do direito, Hegel defende que a insuficiência e limitação de duas concepções de liberdade individual vigentes na sua época são responsáveis pelo surgimento de um sofrimento de indeterminação. A primeira, que Honneth (2015) chama de "modelo negativista", caracterizase pela rejeição subjetiva a todas as limitações à subjetividade; a segunda, o "modelo optativo", parte da ideia de que só podem ser denominadas autônomas ou livres as ações que resultam da autodeterminação racional. Para Hegel (2010), o modelo negativista levaria a uma infinitude irrestrita de uma abstração absoluta, que conduziria os sujeitos à inação; e o optativo levaria a uma posição de deliberação moral de ações e inclinações indisponíveis, 
porque vazias de conteúdos intersubjetivos. Hegel (2010) propõe um modelo comunicativo de liberdade, que recorre às bases conceituais desses dois modelos incompletos de liberdade.

Como Honneth aponta em $O$ direito da liberdade, a questão sobre os limites de concepções de liberdade que partem da ideia de que os indivíduos são livres quando autônomos, livres quando livres de contextos, constrangimentos sociais, normas e símbolos compartilhados previamente não é nova e remonta ao debate entre liberais e comunitaristas sobre o modo como a justiça deveria se constituir. Enquanto, para os primeiros, as normas têm que dar prioridade a uma concepção abstrata de pessoa, cujas capacidades de agir são independentes de contextos sociais e determinações históricas; para os segundos, as normas devem priorizar uma concepção de sujeito vinculada a contextos, histórias, tradições, práticas e valores que formam uma base normativa comum. Para Honneth (2015), a realização individual deveria ser assegurada por uma estrutura de direitos, deveres e liberdades, como defendem os liberais, mas deveria ser deduzida de um contexto ético compartilhado intersubjetivamente, e não deduzida abstratamente, como se constitui na teoria da justiça de John Rawls.

O debate sobre uma teoria da justiça que priorize ou um sujeito abstrato ou um sujeito contextual desemboca em um embate entre concepções de liberdade que ou veem os sujeitos como indivíduos que se constituem independentemente de contextos (liberdades jurídica e moral) ou como dependentes de relações intersubjetivas (liberdade social, como propõe Honneth). Assim, em vez de tomar a normatividade das sociedades democráticoliberais no Ocidente como um processo evolutivo que teria chegado a um ápice na satisfação de demandas individuais dos sujeitos envolvidos, como poderia fazer um liberal inspirado nas ideias procedimentalistas de John Rawls, Honneth (2015) a reconstrói a fim de defender que há debilidades, problemas e más interpretações em uma normatividade capaz de provocar patologias sociais. Assim, a crítica das patologias sociais empreendida por Honneth possui uma construção conceitual bastante específica: ele parte de pretensões normativas de uma determinada época para verificar se, a partir delas, surgiram ou não fendas na autorrealização e nas relações sociais humanas. No entanto, trata-se de um caminho metodológico que deveria evidenciar as contradições e os paradoxos de ideais, concepções e formas de vida já presentes, com o objetivo de encontrar uma possibilidade de realização individual mais coerente, mas que acaba abordando a normatividade das sociedades ocidentais capitalistas de modo a preservá-la de uma crítica radical, como veremos nas críticas tecidas por Schaub (2015), 
Safatle (2016), Culp e Soroko (2015) ao uso da reconstrução normativa como um método de crítica social.

Desse modo, veremos neste artigo como os limites na concepção de liberdade jurídica são responsáveis pela emergência de indivíduos que manifestam sintomas de enfermidades sociais, sendo um deles a incapacidade de estabelecer relações sociais afetivas (I). Também observaremos como os limites na concepção de liberdade moral são capazes de promover sofrimentos como rigidez e engessamento, no caso do surgimento da personalidade do moralista desvinculado que ignora todas as normas existentes (II).

Por último, desenvolveremos, de modo breve, a concepção de liberdade social proposta por Honneth (III), sem deixar de apontar como a crítica das patologias sociais se desmobiliza dentro de um novo espectro de pressupostos que não mais vê "paradoxos" nas esferas de realização individual dos sujeitos (relações pessoais, economia de mercado e formação da vontade democrática), mas apenas “desenvolvimentos errados”, segundo a lógica metodológica da reconstrução normativa (IV). Vê-se, no argumento honnethiano de que a liberdade social deveria ser um ideal norteador das instituições sociais, que o filósofo compra a ideia não só de progresso, como também de um progresso gradual. As sociedades progrediriam se os problemas e obstáculos à realização da liberdade social fossem gradualmente sanados dentro das instituições já existentes. Nessa visão, a teoria crítica se afasta de outra forma possível de progresso: a de um progresso revolucionário, caracterizado pelo abandono de normas em operação por outros complexos de normas que não surgiram simplesmente das normas anteriores, como propõe Schaub (2015).

Ao retomarmos os diagnósticos das patologias das liberdades jurídica e moral, apontaremos também os limites desses diagnósticos quanto à explicação etiológica (causal) para os sofrimentos em questão. Como veremos mais detalhadamente, Honneth indica que, embora ambas as concepções de liberdade tenham aberto caminho, devido aos seus limites, para o surgimento de patologias sociais, a causa em si dessas enfermidades residiria em uma “interpretação errônea” por parte dos sujeitos envolvidos da normatividade de ambas as concepções de liberdade. A crítica ao método de reconstrução normativa, utilizado por Honneth, parece ter uma ligação profunda com o déficit etiológico desses diagnósticos de patologias sociais. O fato de que as patologias sociais se mostrem como problemas de interpretação e erros cognitivos de normas corretas resulta de um posicionamento teórico que acredita na ideia de que se vive em uma sociedade genuinamente livre na qual as normas têm validade por si mesmas. Assim, neste trabalho, também veremos como o déficit etiológico nos 
diagnósticos das patologias das liberdades moral e jurídica tem uma relação bastante intensa com o caminho metodológico escolhido por Honneth em $O$ direito da liberdade: o de uma reconstrução normativa.

\section{PATOLOGIAS DA LIBERDADE JURÍDICA}

Antes de nos voltarmos especificamente para alguns sintomas e causas das patologias da liberdade jurídica, é preciso que compreendamos brevemente a formação e o papel da liberdade jurídica no seio das sociedades modernas. Para Honneth (2015), a noção de que existe uma base jurídica capaz de garantir todas as nossas liberdades ainda é muito influente hoje em dia. Esse ordenamento jurídico, que se constituiu gradativamente na Europa dos séculos XVII e XVIII, passou a assumir os aspectos de um sistema racional-finalista, que não dependia de critérios éticos, nem de um assentimento moral. Como resultado, o que surge é uma soma de direitos subjetivos que situa a vida dos sujeitos individuais como um espaço que deve ser protegido de interferências externas. A liberdade individual, vista a partir de um aspecto jurídico, deve ser mantida longe de influências externas. O direito abstrato, como previu Hegel (apud HONNETH, 2015, p. 132), tinha a dupla função tanto de garantir a solução de questões externas a partir de uma perspectiva racional-finalista como de criar um espaço adequado para que os sujeitos pudessem internamente deliberar, da forma mais eficaz possível, sobre questões éticas. Como explica Honneth (2015, p. 131), o sujeito é compreendido em sua coesão interna como resultado de um esforço para criar uma esfera protegida de intromissões externas, tanto estatais como não estatais, no seio da qual ele desenvolve a sua própria noção de bem. Ao indivíduo, na perspectiva de uma liberdade jurídica de caráter negativo, resta a experiência de explorar a si mesmo unicamente na esfera privada, sem estabelecer um diálogo com uma dimensão social. Nessa perspectiva, só os direitos têm valor. Deveres, vinculações e dependências são considerados apenas bloqueios à própria subjetividade.

Honneth aponta que há um limite nessa liberdade, que é o de não levar em consideração o fato de que a autonomia dos sujeitos depende, em algum grau, de uma integração social. "[...] o caráter incompleto da liberdade entendida pelo viés dos direitos individuais manifesta-se sobretudo no fato de, ao se recorrer a ela, sempre haver a tendência a minar e subverter a rede existente de relações sociais" (HONNETH, 2015, 131). É sacrificada, na liberdade jurídica, toda a possibilidade de estabelecer contatos comunicativos através dos 
quais se torna possível construir autoconcepções profundas, valiosas e precisas. O que ocorre é que se abre uma esfera de liberdade negativa que permite ao sujeito sair do espaço comunicativo dos deveres recíprocos ao mesmo tempo em que lhe dá a oportunidade de problematizar questões da vida a partir de uma ética, mas no isolamento.

Assim, há casos que passam pelas esferas jurídicas que não deveriam negligenciar os aspectos comunicativos e afetivos, como veremos a seguir. Nessas situações, a liberdade jurídica, quando tomada de forma absoluta, pode negligenciar um pano de fundo valorativo, histórias de vida e questões afetivas. Quando isso acontece, surgiriam patologias da liberdade jurídica, como defende Honneth. Casos de divórcio, por exemplo, em que os sujeitos envolvidos passam a se tratar de modo estratégico e abstraem reciprocamente todas as qualidades humanas. Como detalha Honneth (2015, p. 155), "aquele que, para se separar de seu cônjuge, vale-se do direito individual ao divórcio veda àquele toda oportunidade de discutirem juntos, à luz das experiências compartilhadas até aquele momento". Diante desse quadro, surge uma questão: o que, de fato, teria levado os sujeitos a abstraírem as vias comunicativas na resolução de conflitos que deveriam, a priori, ser resolvidos comunicativamente e a levá-los para a esfera jurídica, a qual, como Honneth aponta, tem, como essência, a abstração das exigências intersubjetivas? Nosso filósofo não chega a responder essa questão e, sem dúvidas, há várias respostas disponíveis para essa provocação.

As "influências sociais" que teriam levado os sujeitos a "desaprender" a gramática normativa das esferas ética e jurídica são um mistério na interpretação honnethiana - e nisso reside o déficit etiológico que desejamos enfatizar na leitura empreendida por Honneth das patologias das liberdades. No nível subjetivo, não há uma explicação mais profunda para essas desordens de segunda ordem. De maneira simplista, Honneth (2015) atribui a causa para a disposição em adotar a perspectiva da liberdade jurídica de modo absoluto à "tendência social" de atribuir a tarefa de resolver conflitos sociais, de modo rápido e automático, ao sistema jurídico. Por outro lado, em um nível objetivo, a abertura da concepção de liberdade jurídica para uma interpretação errônea já fica mais evidente. Seguindo a leitura honnethiana, fica claro que a liberdade jurídica não se trata de uma concepção universalizável para todos os contextos sociais e que, nas situações em que as relações intersubjetivas devem ganhar protagonismo, a interpretação dos fatos segundo aspectos puramente jurídicos é simplesmente inadequada, para não dizer patológica.

A partir do filme Kramer vs. Kramer e do romance Michael Kohlhaas, Honneth explica um dos sintomas das patologias da liberdade jurídica: aquele em que os sujeitos veem 
uns ao outros apenas como sujeitos de direitos. O agir comunicativo seria necessário na resolução de tais conflitos, mas o que ocorre é que ele é completamente esquecido diante de uma espécie de protagonismo de uma racionalidade jurídica processual, calculista, fria e finalista. Nesses casos, o motivo original do conflito também pode cair em esquecimento e, então, o meio para se atingir um fim é visto como o fim em si. O personagem Michael Kohlhaas, por exemplo, após uma experiência de injustiça, assume uma personalidade que, no curso de intrigas e brigas, mostra-se crescentemente jurídica e passa a proceder apenas como personalidade jurídica. No filme Kramer vs. Kramer, ocorre uma situação semelhante: um pai e uma mãe recém-separados buscam, cada um, ter a guarda incondicional do filho em tribunal norte-americano. $\mathrm{O}$ que ocorre é que eles passam a planejar as próprias ações com o filho a fim de terem êxito em um tribunal e perdem o sentido para os assuntos e propósitos que não estão sujeitos à articulação jurídica. “[...] impõe-se sucessivamente um modo de comportamento no qual os sujeitos aprendem a observar suas próprias intenções e aquelas de suas contrapartes sob o aspecto de sua utilidade jurídica." (HONNETH, 2015, p. 165). Assim, os atos de cuidado, amor e dependência com o filho, em Kramer vs. Kramer, ganham valor apenas quando são passíveis de ser publicamente demonstrados no tribunal.

A causa da "má interpretação" não fica evidente, talvez pelo fato de que não haja um motivo único. O limite etiológico é claro, quando não se identifica o que teria levado os sujeitos, de fato, a interpretarem de modo errôneo essas concepções de liberdade, mas já há uma espécie de avanço em direção a esse diagnóstico etiológico, quando se passa a identificar as promessas normativas de determinadas formas de liberdade e os casos nos quais essas promessas não são realizadas. Provavelmente, como indicou Safatle (2016), seria preciso ir além do argumento de que os sujeitos simplesmente vivenciam uma espécie de distorção cognitiva da gramática de ações sociais e questionar o potencial dessa gramática de realmente conduzir os sujeitos a se realizarem individualmente. Ou, como propõe Freyenhagen (2015, p. 143):

Não é uma surpresa ver que Honneth em $O$ direito da liberdade não pensa nas patologias sociais e em outras aberrações sociais como indicadores de um mundo social que só poderia ser transformado com revoluções. $\mathrm{Na}$ verdade, elas são compreendidas segundo o modelo de uma crítica imanente com orientação normativa: como desvios de normas que já estavam incorporados na fábrica social e que poderiam ser transformadas sem mudanças radicais. 
De todo modo, a tomada absoluta de uma perspectiva de liberdade que tem seus limites impede que aspirações e intenções de alcance profundo e de natureza dialógica se constituam. Identificar como isso acontece, sem dúvida, não é uma tarefa fácil, mas se trata de um empreendimento teórico necessário que pode deixar mais claro como se desenvolvem determinadas experiências de sofrimento e como elas podem ser abandonadas a fim de que possamos nos colocar novamente em uma posição de diálogo com o mundo. Apenas intersubjetivamente, como defende Honneth, somos capazes de ser livres. No ideal de liberdade social, proposto por Honneth e inspirado na eticidade hegeliana, encontraremos uma terapia para as patologias apresentadas. Por outro lado, também é na proposta da liberdade social que identificaremos uma das maiores polêmicas do trabalho honnethiano: atribuir às esferas das relações íntimas, do mercado e do Estado democrático o papel de realização dessa liberdade social, sem levar em consideração que os problemas que interpreta como "desenvolvimentos errados" nessas três esferas poderiam ser lidos de modo mais adequado se fossem vistos como questões paradoxais mais profundas, e não como simples "erros". Antes disso, é preciso compreender o significado de liberdade moral e como esta concepção limitada pode provocar patologias sociais.

\section{PATOLOGIAS DA LIBERDADE MORAL}

Antes de desenvolver a sintomatologia das patologias da liberdade moral, é necessário entender como a liberdade moral se caracteriza, quais são os seus limites e, por último, como uma tomada absoluta da concepção de liberdade moral nas mais diversas experiências humanas se manifesta na forma de patologias da liberdade moral. Como já foi dito anteriormente, há um limite etiológico no diagnóstico das patologias da liberdade realizado por Axel Honneth. O diagnóstico de patologia a que nos voltamos agora se desenvolve segundo uma crítica imanente com orientação normativa de duas concepções de liberdade, a fim de mostrar que há, sim, uma ligação entre enfermidade social e promessas normativas não realizadas. Em alguns momentos, não fica evidente, no entanto, os motivos pelos quais os sujeitos "interpretam mal” tais promessas normativas. Na análise honnethiana, não está claro como as imagens limitadas de liberdade simplesmente nos capturaram. De todo modo, é possível imaginar que as causas desses "erros internos" são bastante complexas e, de modo algum, unívocas. 
A concepção de liberdade moral, como reconstrói Honneth, remonta a Kant, cuja noção de autonomia moral lança, pela primeira vez, a ideia de que os indivíduos podem realizar a própria liberdade individual quando se submetem a princípios morais considerados corretos. Kant defende que a verdadeira liberdade dos sujeitos só se constitui quando eles se submetem a uma lei moral considerada correta e racional por todos os sujeitos do mundo. Tal ideia de autonomia moral se constituiria em duas etapas, como concebe Honneth (2015, p. 178): 1) os sujeitos só são livres se suas ações dependerem de uma autodeterminação racional, e não de uma espécie de sujeição a impulsos naturais; 2) as ações dos sujeitos precisam levar em consideração que os outros seres envolvidos também são seres que se autodeterminam; em outras palavras, essas ações devem ter a qualidade da universalidade social. A partir dessa dupla exigência, Kant conclui, de maneira radical, que os seres só são livres quando orientam as próprias ações segundo a lei moral. A partir de uma leitura negativa, a autonomia moral também significa não se sujeitar a circunstâncias sociais que não passaram pela prova da universalidade social.

Não se trata, por outro lado, de uma autonomia livre de normas. A autonomia moral, como afirmou Kant (apud HONNETH, 2015, p. 185), depende da aplicação do imperativo categórico, porque toda determinação reflexiva do agir humano depende que obedeçamos a leis autoimpostas, que possibilitam aos sujeitos dar consistência às suas manifestações e excluir a possibilidade do mero acaso. Para Kant, a única fonte dessas leis universais era o imperativo moral, sem levar em consideração a identidade prática de um sujeito como primeira instância, segundo intérpretes de Kant, mais recentemente. De todo modo, o que se defende de maneira irrestrita é que a liberdade individual só pode ser entendida se estiver vinculada a normas morais que devem possuir um caráter estritamente universalista. Em caso de conflitos com as normas, o que se prevê, na liberdade moral, é a capacidade de se separar de todas as vinculações e obrigações existentes para, então, determinar uma nova atitude a partir de uma base já existente de considerações generalizáveis. Como detalha Honneth (2015, p. 191), "tão logo entramos em conflito com outros, devemos estar sempre em condições, de maneira fictícia ou real, de nos retirarmos, sozinhos ou em conjunto, do leito em que correm nossas eticidades do mundo real, sem pôr a perder a aprovação da comunidade".

No entanto, essa capacidade de se afastar, que ocupa um lugar legítimo nas sociedades altamente desenvolvidas, deveria, para Honneth, ser apenas um estágio em um processo amplo de verificação que leva em consideração o fato de que um ponto de vista a ser moldado já tem, desde o princípio, a forma de uma realidade social prévia. O problema, a 
falha, a "má-interpretação" acontecem quando essa capacidade de se afastar revela seu lado sombrio, quando os sujeitos não são mais capazes de voltar a uma realidade social prévia, quando não veem que as próprias ideias morais só são formadas dentro de um universo simbólico moral já compartilhado anteriormente. Exercer a liberdade moral, segundo Honneth (2015, p. 194), significa tomar parte em uma esfera de interação que tem um saber compartilhado e interiorizado, porque é regulada por normas de reconhecimento recíproco. Os indivíduos devem ser aptos a justificar intersubjetivamente as próprias decisões, sendo capazes de defendê-las com argumentos convincentes para todos.

Para Honneth, a causa das patologias da liberdade moral parece residir no próprio sujeito. Para nosso autor, são justamente os membros da sociedade que se equivocam sistematicamente quanto ao significado racional de uma forma de prática institucionalizada em uma sociedade. Resumidamente: há limites na normatividade das liberdades jurídica e moral (assim como há limites em um sem-número de normatividades), mas, apesar do mérito de esses limites terem sido levados em consideração na análise sem dúvidas mais complexa empreendida por Honneth, quem não viu os limites e se equivocou foi o sujeito. Surgem, então, as perguntas: por que eles teriam se equivocado? Simplesmente por que essas concepções de liberdade estão abertas a equívocos? O que, de fato, está por trás de uma interpretação errada de uma concepção de liberdade que, assim como tantas outras concepções normativas das sociedades liberais-democráticas, tem os seus limites? Trata-se de questionamentos que não encontram resposta na interpretação honnethiana e por isso o déficit etiológico do diagnóstico desenvolvido pelo nosso autor se concentra especificamente no aspecto subjetivo da análise, e não no objetivo, o qual, através de um resgate das pretensões normativas de ambas as concepções de liberdade, já se explica por si só. Assim, a etiologia da enfermidade em questão deve ser buscada também no sujeito, no aspecto subjetivo, não apenas no objetivo, uma vez que a patologia só se constitui a partir dessa relação produtiva e, muitas vezes, desconcertante entre ideais e sujeitos, normas e indivíduos.

Voltamo-nos às manifestações de patologia da liberdade moral no exemplo da personalidade do moralista desvinculado. Nesse caso, o sujeito se mostra isolado socialmente, não consegue se comunicar e demonstra rigidez e engessamento. Assume a máscara de um moralista que ignora todas as normas sociais existentes, porque as considera sem validade, mas quer estender as próprias normas para um todo social como se elas fossem mais adequadas. “[...] tão logo se tenha procedido como se já não fôssemos previamente obrigados por normas de ação elementares, surge a ficção de um sujeito desvinculado, que tem de obter 
todos os seus princípios pela perspectiva abstrata de uma humanidade universal." (HONNETH, 2015, p. 213). Nosso autor traz o exemplo dos protagonistas dos livros do escritor norte-americano Henry James. Todos eles, preocupados com princípios morais universais, esquecem onde estão os deveres mais próximos ou não veem que existem problemas morais próximos que poderiam ser combatidos. Tanto Henry como o seu irmão, William James, concordavam que a autonomia moral se mostra limitada quando compreendida como uma exortação à adoção de um ponto de vista incondicionado e socialmente não mediado.

Vimos, então, que uma etiologia completa das patologias analisadas precisa passar pela resposta à pergunta: por que os sujeitos compreendem erroneamente o significado de concepções limitadas de liberdade individual? Resgatar a normatividade dessas concepções e revelar que há limites nelas não é suficiente na investigação das causas das patologias analisadas, uma vez que a atividade dos sujeitos é fundamental na compreensão dos motivos pelos quais um modo de proceder que deveria ficar restrito a um determinado contexto acaba se espalhando para domínios cuja lógica é outra. Entender o que aconteceu com os sujeitos, portanto, é fundamental na gestação das causas para a patologia em questão.

Veremos agora como o ideal de liberdade social se mostra, na estrutura do pensamento honnethiana, como uma terapia para as patologias apresentadas. A solução apresentada por Honneth já contém várias outras problemáticas e polêmicas, sendo uma delas a visão de que sofrimentos e enfermidades provocados pela esfera do mercado são apenas "desenvolvimentos errados" de uma promessa de garantia da liberdade social inerente à própria esfera do mercado, e não "paradoxos" fundamentais que sustentam o mercado ideologicamente. Essas questões serão apresentadas apenas de modo breve, uma vez que o debate entre mercado e ética é vasto, delicado e controverso. Para não sacrificar a riqueza dele, trataremos apenas de um problema específico: a defesa honnethiana de que esferas específicas só se sustentam porque guardam, dentro de si mesmas, a promessa de garantir a liberdade social afasta-se de uma crítica das patologias sociais.

\section{LIBERDADE SOCIAL COMO TERAPIA}

Em Sofrimento de indeterminação, publicado em 2001, Axel Honneth retoma algumas ideias apresentadas por Hegel em Filosofia do direito, a fim de reatualizar esta obra, e planta as sementes para $O$ direito da liberdade, publicado só dez anos depois. Honneth 
retoma, em Sofrimento de indeterminação, a ideia hegeliana de que seria apenas no dever e na relação com os outros que os sujeitos poderiam se libertar, finalmente, para uma liberdade substancial. O significado de "eticidade" na obra hegeliana revelaria, segundo Honneth, a noção terapêutica de que seria apenas em relações sociais que, por si sós, já abrangem direitos e deveres, que poderíamos nos libertar do "vazio torturante para o qual a autonomização do ponto de vista moral nos levou" (HONNETH, 2007, p. 98). Só as relações sociais seriam capazes, portanto, de "nos curar" da noção errônea e esvaziada de que a liberdade real consistiria na desobstrução e dissolução de relações sociais capazes de impedir a realização da liberdade. O sentido fundamental da eticidade, na obra hegeliana, seria o de libertar o sujeito duplamente: o indivíduo tanto estaria livre de duas perspectivas altamente unilaterais de restrição da liberdade (jurídica e moral) como também poderia se voltar para um tipo de liberdade mais consistente, a liberdade social, incorporada nas relações éticas. A libertação dos sujeitos de patologias sociais só poderia acontecer a partir de uma virada em direção a um conceito de justiça, concebido segundo uma teoria da intersubjetividade, como aponta Hegel.

Não entraremos aqui em mais detalhes sobre as instituições sociais que, para Hegel, encarnavam o princípio de eticidade, mas é preciso enfatizar que a noção de liberdade social apresentada por Honneth é um desdobramento da ideia hegeliana de eticidade. Honneth defende que, nas sociedades moderno-capitalistas, as esferas institucionais das relações pessoais, da economia de mercado e da vontade democrática são três sistemas de ação nos quais a liberdade social pode ser realizada, também em um desdobramento das esferas éticas de realização individual pensadas por Hegel. Para Honneth, a noção de liberdade social pressupõe a formulação hegeliana de "estar consigo mesmo do outro", que traduz a ideia de que o sujeito só pode se realizar individualmente se a sua realização individual depender da realização individual de outros sujeitos. A liberdade social vem, então, com novos paradigmas:

\footnotetext{
A aspiração à liberdade deixa de ser um elemento da experiência puramente subjetiva no momento em que o sujeito se encontra com outros sujeitos cujos objetivos se comportam de maneira complementar aos próprios, uma vez que agora o ego pode ver, nas aspirações de outra parte na interação, um componente do mundo externo que lhe permite colocar em prática objetivamente as metas estabelecidas por ele mesmo. (HONNETH, 2015, p. 85-86).
}

Com a liberdade social, as formas de liberdade que não levam em consideração o aspecto objetivo ou a realidade social de modo adequado perdem o significado. A realidade 
deixa de ser, na ideia de liberdade social, um obstáculo para a realização da liberdade, como vimos nas noções de liberdade moral e jurídica, mas passa a ser componente mesmo de realização da liberdade. Essa concepção desemboca em formas diferentes de lidar com as relações sociais: os indivíduos, ao se depararem com o ego do outro, reconhecem a realização do desejo do outro como condição de contentamento de seu próprio desejo. Não se trata mais de ver a concretização do desejo do outro como obstáculo para o próprio, mas como condição. Nas relações familiares, por exemplo, a realização do meu desejo de ser amada é condição para a realização do desejo dos meus filhos de darem amor, por exemplo, e vice-versa. Nas relações de mercado, a realização do meu desejo de ter dinheiro para comprar alimentos seria pré-condição de satisfação do desejo de outro sujeito para obter dinheiro a partir dessa venda para também comprar alimentos, em um ciclo mútuo de satisfação de demandas.

É a partir desse pressuposto que Honneth, em uma das partes mais controversas de $O$ direito da liberdade, desenvolve a ideia de que os problemas da economia de mercado são anomalias sociais que devem ser retificadas dentro da própria estrutura de mercado, uma vez que esta, segundo o seu argumento, de fato consiste em uma esfera de realização da liberdade dos sujeitos. Não entraremos nessa discussão de maneira ampla, porque se trata de uma questão bastante delicada e que necessitaria de um trabalho à parte para que a relação entre mercado e moral fosse analisada e problematizada adequadamente. Apresentaremos aqui apenas parte da defesa de Honneth. No subcapítulo $O$ "nós" do agir em economia de mercado, o filósofo se alinha à tradição que ele chama de "economismo moral", de Hegel e Durkheim, em contraponto à tradição marxista. Para Marx, os problemas mais profundos do capitalismo se tratam de problemas estruturais que não podem ser solucionados a não ser fora do capitalismo, em outro tipo de sistema econômico, pois este sistema em questão, com o seu necessário trabalho denigrativo e sua necessária exploração econômica, não pode jamais conduzir ao prometido aumento da liberdade. Honneth estaria, por outro lado, mais alinhado às visões de Hegel e Durkheim sobre os problemas do capitalismo. Para estes, a esfera de ação mediada pelo mercado só poderá satisfazer a função de integrar, sem coerção e em harmonia, as atividades econômicas dos indivíduos mediante relações contratuais se estiver ancorada em uma consciência de solidariedade. Para ambos, se o capitalismo não guardasse, em si, a promessa de integrar harmonicamente os interesses econômicos individuais, ele simplesmente não existiria. Mas, como ele guarda essa promessa, isso quer dizer que, na prática, quando ele parece não realizar a promessa de harmonia de interesses, teria acontecido algum tipo de "desenvolvimento errado". Para ambos "o novo sistema da economia de 
mercado [...] não pode ser analisado sem uma classe de regras morais não contratuais que lhe precedem; caso contrário, não estaria em condições de satisfazer a função [...] de integrar harmonicamente interesses econômicos individuais" (HONNETH, 2015, p. 336).

Assim, para Honneth, apoiado em Hegel e Durkheim, os problemas apontados por Marx da exploração econômica e dos contratos impostos (este último refere-se ao fato de que as partes contratuais jamais terão direitos iguais se uma das partes tem apenas a sua força de trabalho como mercadoria) no capitalismo deveriam ser entendidos não como déficits estruturais que só poderiam ser eliminados fora da economia de mercado capitalista, mas como desafios produzidos pela própria promessa normativa do capitalismo e, portanto, apenas superáveis dentro dele mesmo. Além disso, o fato de existirem movimentos sociais, protestos a favor de uma moralização do mercado e reformas políticas direcionadas a lapidar os desenvolvimentos tortuosos do capitalismo seria por si só uma comprovação de que o capitalismo não só possui, em si, uma promessa normativa de realização da liberdade dos sujeitos como também é capaz de efetivá-la. Há uma série de críticas a essa defesa empreendida por Honneth da esfera de mercado no capitalismo, como as críticas de Allen (2016), Freyenhagen (2015), Pinzani (2013), Safatle (2016) e Schaub (2015) - críticas que questionam principalmente a validade da reconstrução normativa como método de uma crítica social radical.

A seguir, veremos como o déficit etiológico no diagnóstico das patologias das liberdades está bastante ligado ao uso da reconstrução normativa como caminho metodológico. Ao trazer o método de reconstrução normativa, Honneth tem o intento de aperfeiçoar instituições e práticas dentro de seus próprios paradigmas, em uma espécie de validação do já existente. A partir dessa estratégia, o filósofo parece negligenciar o significado da negatividade, o potencial revolucionário daquilo que "não se encaixa", o caráter denunciador do sofrimento. Ao abordar as patologias das liberdades jurídica e moral, Honneth situa no sujeito a responsabilidade pelos próprios sofrimentos, sem desenvolver de modo convincente o motivo pelo qual os indivíduos "se confundem" ao absolutizar concepções de liberdade limitadas. Quando se refere aos sofrimentos que ele chama de "desenvolvimentos errados", o caráter restaurador da reconstrução normativa se torna ainda mais evidente. 


\section{PROBLEMAS DA RECONSTRUÇÃO NORMATIVA COMO MÉTODO}

É curioso perceber que a crítica de Honneth ao neokantismo de John Rawls, que enfatiza que uma teoria pouco contextual falharia na análise de práticas correntes de opressão e dos modos pelos quais essas práticas moldam as instituições sociais e as premissas epistêmicas do presente, parece ser inconsistente diante do projeto filosófico desenvolvido por Honneth em $O$ direito da liberdade. Como aponta Culp e Soroko (2015), em que ponto exatamente o resultado da reconstrução normativa empreendida por Honneth é tão diferente dos projetos filosóficos de viés kantiano? "A metodologia de Honneth não é procedimentalista, mas ela sofre dos mesmos males que ele identifica nas abordagens kantianas [...], uma vez que ele não pode explicar de onde vêm os valores que sustentam as sociedades tidas como livres e como eles ganharam legitimidade" (CULP; SOROKO, 2015, p. 3). Ainda que Honneth tente justificar os valores éticos que sustentam as sociedades moderno-capitalistas a partir de exemplos históricos variados, não quer dizer que o fato de as pessoas cobrarem das instituições sociais determinados valores éticos que essas instituições realmente os possuam. Desse modo, o que se vê é uma espécie de neokantismo na estratégia honnethiana de atribuir pretensões éticas a instituições e práticas que, a nosso ver, não necessariamente as possuem porque são cobradas a terem-nas. No entanto, é fato que, do ponto de vista metodológico, a abordagem de Honneth poderia ser interpretada mais como uma crítica interna de viés restaurador, enquanto que a de Rawls parece situar os seus critérios fora do objeto analisado.

Enquanto que, em Luta por reconhecimento, publicado em 1992, Honneth (2003b) concebe a existência de conflitos sociais no seio do mundo da vida e no espaço das relações intersubjetivas segundo uma reconstrução normativa negativa, mostrando como a negação do reconhecimento é danosa para a constituição psíquica de indivíduos imersos em relações morais de reconhecimento; em $O$ direito da liberdade, publicado em 2007, Honneth segue o caminho de uma reconstrução normativa positiva ao conceber as pretensões normativas de instituições e se voltar para aqueles sofrimentos que eclodem a partir da relação entre indivíduos e instituições. No entanto, $O$ direito da liberdade tenta solucionar uma espécie de déficit sistêmico encontrado em Luta por reconhecimento. Nesta obra, de 1992, Honneth busca apreender uma normatividade inexistente na concepção de mundo da vida de Habermas, mas, por outro lado, não chega a problematizar a constituição normativa das instituições e o potencial delas de afetar e conformar os sujeitos. É assim que, em $O$ direito da 
liberdade, as instituições ganham protagonismo, e os sofrimentos aparecem como resultado de relações complexas entre as instituições e os indivíduos - alguns deles interpretados como "desenvolvimentos errados" e outros como patologias sociais. O caminho de Luta por reconhecimento até $O$ direito da liberdade, assim, é permeado por reflexões que questionam o papel das instituições na constituição psíquica dos sujeitos e na formação de seus modos de vida, como vimos nos artigos nos quais Honneth refere-se, por exemplo, às patologias do individualismo ou ao reconhecimento ideológico, como veremos adiante. No entanto, isto não quer dizer que as instituições tenham sido adequadamente problematizadas em $O$ direito da liberdade, que parece desenvolver uma teoria da justiça, em vez de uma teoria crítica. Nesse aspecto, parece que há uma perda do potencial crítico em Luta por reconhecimento, obra de 2011.

O ponto é que Honneth chega a identificar o vácuo entre ideais normativos e realidade, entre fatos e normas na modernidade capitalista, trazendo o conceito de paradoxo nos artigos Paradoxes of capitalism (HONNETH; HARTMANN, 2006) e Organized selfrealization (HONNETH, 2004), mas o que ele parece defender, em trabalhos posteriores como $O$ direito da liberdade, é que os obstáculos à realização individual teriam sido causados por normas que foram deturpadas - e não por uma relação inversa entre normas e fatos, como é possível ver em trabalhos anteriores a $O$ direito da liberdade. Para Pinzani (2013), quando Honneth aborda os problemas que impedem a realização dos indivíduos sem recorrer ao conceito de paradoxo, ele normalmente recai em uma crítica social que vê, nos problemas da modernidade, um desenvolvimento errado (Fehlentwicklung) de normas realizáveis, e não um desenvolvimento correto de normas intencionalmente irrealizáveis. Enquanto, antes de $O$ direito da liberdade, Honneth recorre ao conceito de paradoxo para realizar uma espécie de crítica interna às sociedades sob o neoliberalismo, nesta obra o filósofo segue os caminhos metodológicos que ele chama de "reconstrução normativa" - e vem dessa estratégia metodológica o abandono do conceito de paradoxo em prol da ideia de "desenvolvimento errado". Pode-se dizer que, em $O$ direito da liberdade, a crítica social torna-se menos crítica e mais restauradora - se é que se pode chamar de crítico o empreendimento teórico encontrado nesta obra.

De maneira breve, em $O$ direito da liberdade, Honneth apresenta a reconstrução normativa em quatro premissas. São elas: 1) a reconstrução normativa parte do pressuposto de que as ordens sociais precisam se legitimar segundo valores éticos e ideais valorativos diante de todos os membros da sociedade; 2) ela também supõe que as nossas noções de justiça 
dependem de valores éticos que já estão embutidos nas instituições sociais responsáveis pela reprodução social; 3) a reconstrução normativa deve selecionar instituições e práticas já existentes que precisam ser reconstruídas normativamente e 4) ela consistiria em uma espécie de crítica interna que não deveria apenas afirmar a existência de instâncias de uma vida ética, mas também precisaria revelar até que ponto instituições e práticas não representam os valores gerais que elas encarnam de modo convincente ou completo. Desse modo, o filósofo busca resgatar e reconstruir as pretensões normativas de instituições já existentes. Em suma, o que a reconstrução normativa faz é "avaliar se estas instituições e práticas éticas poderiam realizar os valores que elas encarnam de um modo mais adequado e completo" (HONNETH, 2015, p. 26). A "crítica reconstrutiva" tecida por Honneth teria o intento de aperfeiçoar instituições e práticas dentro de seus próprios paradigmas, em uma espécie de validação do já existente.

Trata-se de uma estratégia metodológica bastante polêmica e criticada. Para Schaub (2015), por exemplo, a reconstrução normativa, ao contrário do que defende Honneth, é um método não só inadequado como também inaceitável para sustentar uma teoria crítica da sociedade $^{1}$. Seguindo os argumentos de Honneth delineados no capítulo Redistribution as recognition, encontrado na obra Redistribution or recognition? a political-philosophical exchange (HONNETH; FRASER, 2003), de que revoluções normativas ocorrem sem que as novas normas fossem subjacentes à normatividade, Schaub defende que uma crítica radical se refere àquilo que não está "por trás” de instituições sociais já existentes, reproduzidas e reprodutoras de práticas sociais.

Eu teço esta crítica a partir de uma leitura de um Honneth (obras nem iniciais nem finais) contra outro Honneth (últimas obras), uma vez que eu recorro a noções de revolução normativa e crítica radical do próprio Honneth. O centro do meu argumento é que a teoria crítica requer um método que, diferentemente da reconstrução normativa, esteja aberto à possibilidade de revoluções normativas e que não vire as costas para uma crítica radical. (SCHAUB, 2015, p. 109).

No entanto, parece que, nos seus trabalhos mais recentes, Honneth tem interpretado as promessas normativas das sociedades ocidentais capitalistas como, de fato, realizáveis

\footnotetext{
${ }^{1}$ Schaub não entra nos problemas enfrentados pela crítica interna como método. Há limitações relevantes nesse recurso metodológico que não desenvolveremos aqui, porque exigiria entrar em um debate exaustivo que extrapola as intenções deste texto. Para se livrar desse compromisso, Schaub apenas justifica que a reconstrução normativa, enquanto método, compromete fortemente a ligação da teoria crítica com uma crítica mais radical capaz de catalisar revoluções normativas. De fato, o problema da reconstrução normativa não se encontra presente em todos os tipos de críticas internas, já que muitas delas estão abertas à possibilidade de que instituições existentes e reprodutivamente relevantes são incapazes de realizar as normas que as sustentam - o que a reconstrução normativa, concebida por Honneth, nega.
} 
dentro delas - negando a sua ideia anterior de que as promessas normativas do capitalismo neoliberal são irrealizáveis dentro dele, por serem paradoxais. Dessa maneira, as experiências de sofrimento não denunciariam mais o aspecto problemático do sustentáculo de nossas sociedades neoliberais, mas seriam interpretadas como "desenvolvimentos errados" de algo que tem a pretensão de criar causas e condições para a realização individual. As patologias do individualismo não ganham espaço, portanto, na obra $O$ direito da liberdade. Quando muito, as patologias da liberdade individual, que são interpretadas nesta obra, demonstram apenas uma espécie de "erro cognitivo" de sujeitos que não perceberam que determinados ideais de liberdade deveriam ficar restritos a domínios sociais específicos, e não absolutizados para todas as esferas sociais. Não se problematiza, por exemplo, se ideais restritos de liberdade chegam a constituir, de maneira sutil, o modus operandi de instituições sociais cuja normatividade alega um ideal de liberdade distinto. Por exemplo, se a esfera de mercado, cuja pretensão de ser uma esfera de realização da liberdade social, funciona, na prática, segundo um ideal de liberdade mais restrito, como o de uma liberdade negativa que só se realiza com a anulação de obstáculos.

Talvez de modo não intencional, Honneth "vira as costas" para o significado da negatividade, para o potencial revolucionário daquilo que "não se encaixa" nas pretensões normativas de uma sociedade, para o caráter denunciador do sofrimento. Em Marx, o sofrimento social da reificação não resulta de um "desenvolvimento errado" das normas sociais, mas justamente do caráter paradoxal do funcionamento normal das sociedades capitalistas. Parece que Honneth, ao abandonar o conceito de paradoxo em prol de um projeto filosófico de reconstrução normativa das sociedades capitalistas atuais, legitima o estado de coisas a que chegamos e, de modo implícito, acaba propondo que as patologias sociais tenham a sua terapia dentro do próprio sistema em questão. Honneth não realiza aquilo que Safatle, por exemplo, vê como o principal objetivo da crítica social: denunciar o caráter distorcido das formas de vida na modernidade ocidental. "Nesse caso, ela (a crítica social) se transforma em crítica da natureza patológica de tais formas de vida com suas exigências de autoconservação e reprodução social.” (SAFATLE, 2008, p. 123).

É preciso questionar até que ponto a solução para os sofrimentos que vivemos se encontra na ideia de reconciliação como aperfeiçoamento de um progresso histórico, proposta por Honneth, ou se essa solução está posta radicalmente fora do ordenamento social atual, como propõe Safatle (2016, p. 12), seguindo Marx. Em $O$ direito da liberdade, Honneth põe de lado o produtivo conceito de paradoxo em prol da ideia de que os sujeitos movem-se de 
modo cooperativo, negligenciando os processos de disciplina necessários para que essas ações possam aparecer como "cooperativas". Concordamos com Safatle (2016, p. 13) no argumento de que "o mal-estar é um sofrimento social resultante não da desregulação das normas sociais, mas do funcionamento normal da normatividade social, do impacto normal do processo civilizatório".

Nos artigos iniciais de Honneth sobre a autorrealização organizada e os paradoxos do capitalismo, era possível ver a defesa de que apenas na social-democracia as promessas de autorrealização poderiam ser realizadas: o individualismo poderia ser uma ideia pessoal principal de todos os sujeitos; a justiça igualitária poderia ser exercida realmente; a conquista seria a base para a atribuição de status; e o amor e a amizade seriam capazes de satisfazer as carências e desejos dos sujeitos individuais. Isso tudo porque o Estado seria capaz de neutralizar a lógica capitalista do lucro. Não existiam paradoxos na social-democracia, apenas no neoliberalismo. Na obra $O$ direito da liberdade, a ideia de paradoxo desaparece, e o que surge é a defesa de que a autorrealização pode se constituir nas esferas das relações íntimas, do mercado e do Estado democrático. Por outro lado, não se trata exatamente de um desvio de percurso radical, mas de uma reafirmação do que Honneth já defendia anteriormente: a realização individual é possível no capitalismo, desde que o Estado cumpra um papel de regulamentação ${ }^{2}$ e o capitalismo consiga corrigir os erros cometidos até agora. Essa visão está presente tanto nos trabalhos anteriores a $O$ direito da liberdade como nesta obra. O que vemos é que a social-democracia assume, então, a função de ideal normativo crítico - uma questão polêmica que só poderia ser apropriadamente abordada em outro trabalho diferente deste. Por ora, o que se observa é que essa perspectiva despotencializa o que poderia ser uma crítica social realmente contundente.

\section{Referências}

ALLEN, Amy. The end of progress: decolonizing the normative foundations of critical theory. New York: Columbia University Press, 2016.

CAGE, John. Lectures and writings on silence. Hanover: Wesleyan University Press, 1973.

CULP, Julian; SOROKO, Leah. Normative reconstruction without foundation. European Journal of Political Theory, v. 15, n. 2, p. 248-255, 2015.

\footnotetext{
${ }^{2}$ A questão sobre se, de fato, o mercado pode ser uma esfera de autorrealização individual é bastante ampla e complexa e extrapola os limites do presente trabalho. Mais sobre as discussões acerca dos limites éticos do mercado.
} 
FREYENHAGEN, Fabian. Honneth on social pathologies: a critique. Critical Horizons, v. 16, n. 2, p. 131-152, 2015.

HEGEL, G. W. F. Filosofia do direito. São Paulo: Loyola, 2010.

HONNETH, Axel. Patologias da liberdade individual: o diagnóstico hegeliano de época e o presente. Novos Estudos, n. 66, p. 77-90, 2003a.

HONNETH, Axel. Luta por reconhecimento: a gramática moral dos conflitos sociais. São Paulo: Editora 34, 2003b.

HONNETH, Axel. Organized self-realization: some paradoxes of individualization. European Journal of Social Theory, v. 7, n. 4, p. 463-478, 2004.

HONNETH, Axel. Sofrimento de indeterminação: uma reatualização da Filosofia do direito de Hegel. São Paulo: Esfera Pública, 2007.

HONNETH, Axel. O direito da liberdade. São Paulo: Martins Fontes, 2015.

HONNETH, Axel; HARTMANN, Martin. Paradoxes of capitalism. Constellations, v. 13, n. 1, p. 41-58, 2006.

HONNETH, Axel; FRASER, Nancy. Redistribution or recognition? A politicalphilosophical exchange. New York; London: Verso, 2003.

PINZANI, Alessandro. Os paradoxos da liberdade. In: MELO, Rúrion. A teoria crítica de Axel Honneth: Reconhecimento, liberdade e justiça. São Paulo: Saraiva, 2013.

SAFATLE, Vladimir. Em direção a um novo modelo de crítica: as possibilidades de recuperação contemporânea do conceito de patologia social. Trabalho em processo. Acesso em 2016.

SAFATLE, Vladimir. A transformação da crítica da razão em análise de patologias sociais: o caso Theodor Adorno. Philósophos, v. 13, n. 2, p. 117-139, 2008.

SCHAUB, Jörg. Misdevelopments, pathologies and normative revolutions: normative reconstruction as method of critical theory. Critical Horizons, v. 16, n. 2, p. 107-130, 2015. 